\title{
Correlation of CYP1A1 and GSTM1 gene polymorphisms and environmental factors to familial aggregation of esophageal cancer among the Kazakh ethnic group in Xinjiang
}

\author{
M. Zeng, Y. Lv, H.F. Wang, H.A. Yiguli, J.R. Zhang and A. Yisikandaer \\ Department of Radiotherapy of the Chest and Abdomen, \\ Affiliated Tumor Hospital of Xinjiang Medical University, Urumqi, China \\ Corresponding author: H.F. Wang \\ E-mail: wanghf2016@126.com \\ Genet. Mol. Res. 14 (4): 19102-19109 (2015) \\ Received September 2, 2015 \\ Accepted November 3, 2015 \\ Published December 29, 2015 \\ DOI http://dx.doi.org/10.4238/2015.December.29.19
}

\begin{abstract}
This study aimed to investigate the correlation of CYP1A1 and GSTM1 gene polymorphisms and environmental factors to familial aggregation of esophageal cancer (EC) among the Kazakh ethnic group in Xinjiang. CYP1A1 and GSTM1 gene polymorphisms were detected using peripheral blood from 86 subjects belonging to families with EC and 82 control subjects. Additionally, a questionnaire survey was conducted to ascertain environmental risk factors. Combined effects of CYP1A1 and GSTM1 gene polymorphisms and environmental factors in familial aggregation of EC were evaluated. Distribution frequencies of CYP1A1 Mspl and GSTM1 genotypes between EC and control families showed significant differences $(P=0.002, P=0.001)$. Contribution of interaction between CYP1A1 Mspl mutant and GSTM1 deletion polymorphisms to familial aggregation of $\mathrm{EC}$ was significant, with $\mathrm{OR}=3.571(95 \% \mathrm{Cl}=1.738-$ 3.346). Logistic multivariate analysis indicated that familial aggregation of $E C$ is correlated with 3 factors: drinking water, intake of fresh vegetables and fruits, and CYP1A1 Mspl polymorphism $(P=0.005, P=0.013$, and
\end{abstract}


$P=0.001)$. Sufficient intake of fresh vegetables and fruits $(O R=0.278$, $95 \% \mathrm{Cl}=0.137-0.551)$ protected against familial aggregation of $\mathrm{EC}$, while drinking water $(\mathrm{OR}=3.468,95 \% \mathrm{Cl}=1.562-6.551)$ and CYP1A1 Mspl polymorphism $(\mathrm{OR}=2.732,95 \% \mathrm{Cl}=1.741-3.886)$ were the risk factors. In conclusion, CYP1A1 and GSTM1 gene polymorphisms affect familial aggregation of EC among the Kazakh ethnic group in Xinjiang. River water intake and CYP1A1 Mspl polymorphism were risk factors that likely contributed to high incidence of EC among families.

Key words: Kazakh ethnic group; Esophageal cancer family; CYP1A1 gene; GSTM1 gene

\section{INTRODUCTION}

Esophageal cancer (EC) is the most common malignancy among the Kazakh ethnic group in Xinjiang, which is believed to be the result of interactions between genetic and environmental factors. Disordered metabolism of chemical carcinogens contained in food and the environment may contribute to EC. Cytochrome P450 (CYP450) enzymes are essential for the metabolism of compounds and are involved in the activation of carcinogens. Glutathione-S-transferase (GST) is an enzyme involved in catalyzing detoxification of a variety of carcinogens. We detected CYP1A1 and GSTM1 gene polymorphisms in the peripheral blood sampled from EC families and control families of the Kazakh ethnic group. Combining this clinical data with a questionnaire survey related to environmental risk factors, we studied the role of CYP1A1 and GSTM1 gene polymorphisms and environmental factors in familial aggregation of EC among the Kazakh ethnic group in Xinjiang.

\section{MATERIAL AND METHODS}

\section{Subjects}

EC families and control families of the Kazakh ethnic group in North Xinjiang were studied. The following inclusion criteria for EC families were determined based on relevant literature (Zhao et al., 2004): 1) the family consisted of at least two generations, 2) the family had at least two patients with EC, and 3) the family contained first-degree relatives. The inclusion criteria for control families were as follows: the control families lived in the same place and belonged to the same ethnic group as the EC families and the families had similar size and sporadic occurrence of EC. In total, 86 subjects satisfying the criteria for EC families and 82 subjects satisfying the criteria for control families from the Kazakh ethnic group were enrolled from North Xinjiang (Table 1). Signed informed consent was obtained from all subjects.

\section{Questionnaire survey}

The survey included the following details: 1) drinking water (well water or river water intake); 2) history of pasteurization; 3) history of smoking (for 1-10 years, 11-20 years, >20 years); 4) alcohol consumption (yes or no); and 5) diet (eating speed 10-30 min, <10 min; occasional intake of spicy food, frequent intake of spicy food; occasional overeating, frequent overeating; occasional intake of green vegetables, frequent intake of green vegetables; occasional intake of fresh fruits, frequent intake of fresh fruits). 


\section{Gene polymorphism detection}

\section{Sample collection and DNA extraction}

For all subjects, $4 \mathrm{~mL}$ peripheral venous blood was collected and EDTA was added. Blood samples were preserved at $-20^{\circ} \mathrm{C}$ and total DNA was extracted. The tissues were lysed; $\mathrm{RNase} A$ and Proteinase $\mathrm{K}$ were added for RNA and protein digestion, respectively. Extraction and precipitation were carried out to obtain genomic DNA, which was then dissolved in TE buffer and preserved at $-20^{\circ} \mathrm{C}$.

\section{CYP1A1 and GSTM1 gene polymorphism detection}

Reagents used were as follows: DNA Extraction Kit (SK1261, Sangon Biotech (Shanghai) Co., Ltd., China), TaqDNA polymerase [Sangon Biotech (Shanghai) Co., Ltd.], and PCR Purification Kit [SK1141, Sangon Biotech (Shanghai) Co., Ltd.].

The following method was used. CYP1A1 Mspl polymorphism was detected by using Polymerase chain reaction-restriction fragment length polymorphism (PCR-RFLP). The upstream primer of the CYP1A1 Mspl gene was 5'-CAGTGAAGAGGTGTAGCCGCT-3'; the downstream primer was 5'-TAGGAGTCT TGTCTCATGCCT-3'. The PCR reaction system $(25 \mu \mathrm{L})$ consisted of: $2.0 \mu \mathrm{L} 4 \mathrm{X}$ dNTP, $2.5 \mu \mathrm{L}$ 10X buffer, $2.5 \mathrm{mM} \mathrm{MgCl}_{2}, 1 \mu \mathrm{L}$ CYP1A1 primer, $1.0 \mu \mathrm{L}$ TaqDNA polymerase, and $1.5 \mu \mathrm{L}$ DNA template. PCR conditions were as follows: pre-denaturation at $94^{\circ} \mathrm{C}$ for $5 \mathrm{~min} ; 94^{\circ} \mathrm{C}$ for $1 \mathrm{~min}, 63^{\circ} \mathrm{C}$ for $1 \mathrm{~min}$, and $72^{\circ} \mathrm{C}$ for $1 \mathrm{~min}$ for $35 \mathrm{cycles}$; and final extension at $72^{\circ} \mathrm{C}$ for $5 \mathrm{~min}$. The length of the amplified product was $340 \mathrm{bp}$. After digestion with the restriction endonuclease Mspl, genotype analysis was carried out using $2 \%$ agarose gel electrophoresis with ethidium bromide staining.

Homozygous deletion of the GSTM1 gene was detected using multiprimerPCR. The common GSTM1 gene primers were as follows: GSTM1-P1, 5'-CGCCATCTTGTGCTACATTGCCCG-3'; downstream primer, GSTM1-P2, 5'-ATCTTCTCCTCTTCTGTCTC-3' and GSTM1-P3, 5'-TTCTGG ATTGTAGCAGATCA-3'. $\beta$-globin was used as positive internal control. The $25 \mu \mathrm{L}$ PCR reaction system consisted of $3.0 \mu \mathrm{L} 4 \mathrm{X}$ dNTP, $2.5 \mu \mathrm{L} 10 \mathrm{X}$ buffer, $3.0 \mathrm{mM} \mathrm{MgCl}, 1 \mu \mathrm{L}$ each GSTM1 and $\beta$-globin primer, $1.5 \mathrm{U}$ TaqDNA polymerase, and 1.0 $\mu \mathrm{L}$ DNA template. PCR conditions were as follows: pre-denaturation at $94^{\circ} \mathrm{C}$ for $4 \mathrm{~min} ; 94^{\circ} \mathrm{C}$ for $1 \mathrm{~min}, 63^{\circ} \mathrm{C}$ for $1 \mathrm{~min}$, and $72^{\circ} \mathrm{C}$ for $1 \mathrm{~min}$ for 35 cycles; final extension at $72^{\circ} \mathrm{C}$ for $10 \mathrm{~min}$. Genotype analysis was carried out using $2 \%$ agarose gel electrophoresis with ethidium bromide staining.

\section{Statistical analysis}

Statistical analysis was performed using SPSS 16.0 software. Differences between the two groups was analyzed by the chi-square test and $t$-test. The expressions of the CYP1A1 Mspl and GSTM1 genes were compared between the two groups by the chi-square test, measuring the odds ratio $(\mathrm{OR})$ and $95 \% \mathrm{Cl}$. All tests were two-sided with a significance $\alpha=$ 0.05 . Logistic regression analysis was used to analyze the correlation of environmental factors (smoking, alcohol consumption, intake of spicy, salted, and smoked food, source of drinking water, intake of fresh vegetables and fruits) and CYP1A1 and GSTM1 gene polymorphisms to familial aggregation of EC. 


\section{RESULTS}

\section{Balance of baseline data}

The composition of the two groups did not differ significantly in terms of gender, occupation, and incidence of EC; the mean age of the two groups did not show any significant difference either. Thus, the baseline characteristics of the two groups were balanced (Table 1).

Table 1. Baseline characteristics of the two groups.

\begin{tabular}{|c|c|c|c|c|c|c|c|c|c|}
\hline & \multicolumn{2}{|c|}{ Gender } & \multicolumn{2}{|c|}{ Age } & \multicolumn{3}{|c|}{ Occupation } & \multicolumn{2}{|c|}{ Incidence } \\
\hline & Male & Female & Range & Mean & Herders & Farmers & Others & EC patients & Non-EC patients \\
\hline EC family & 40 & 46 & $21-81$ & 42 & 27 & 29 & 30 & 36 & 50 \\
\hline Control family & 42 & 40 & $20-79$ & 47 & 26 & 27 & 29 & 38 & 44 \\
\hline$P$ value & 0.410 & & & 0.231 & 0.353 & & & 0.284 & \\
\hline
\end{tabular}

\section{Genotyping}

\section{Detection of CYP1A1 Mspl polymorphism by electrophoresis}

As shown in Figure 1, CYP1A1 wild-type homozygote (T/T) was amplified into one 340-bp fragment (genotype A); the CYP1A1 heterozygous mutant (T/C) was amplified into three fragments (340, 200, and $140 \mathrm{bp}$ ) (genotype B); and the CYP1A1 homozygous mutant (C/C) was amplified into two fragments (200 and $140 \mathrm{bp}$ ) (genotype C).

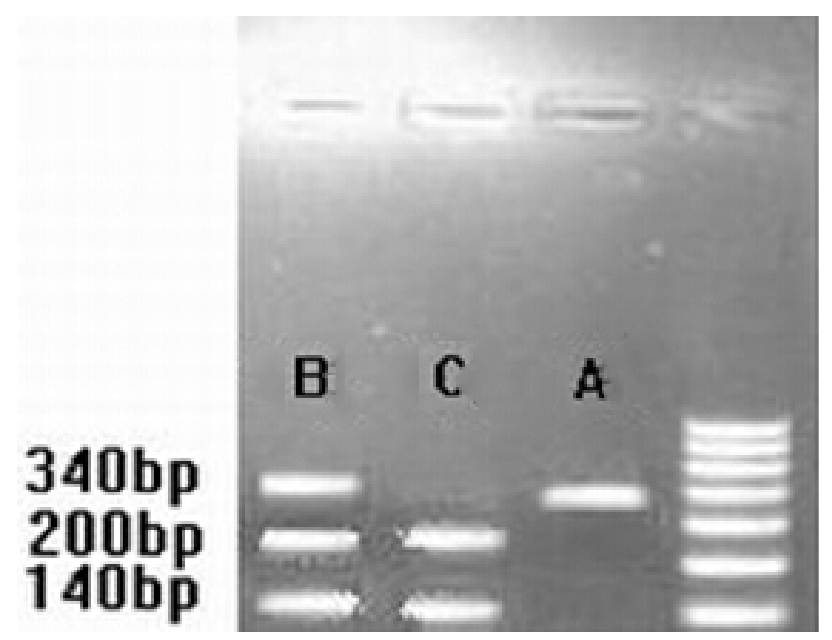

Figure 1. Electrophoretogram of different CYP1A1 Mspl genotypes.

\section{Detection of GSTM1 polymorphism by electrophoresis}

As shown in Figure 2, amplification of both 157 and 230 bp fragments indicated the wildtype genotype (+), and amplification of the 157 bp fragment alone indicated the null genotype (-). 


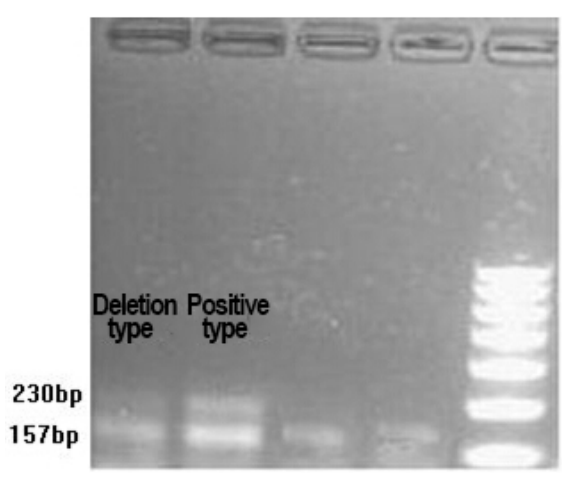

Figure 2. Electrophoretogram of different GSTM1 genotypes.

\section{Correlation of CYP1A1 and GSTM1 gene polymorphisms to familial aggregation of EC}

Among EC families, there were 13 subjects with CYP1A1 wild-type genotype (T/T) $(7.7 \%)$ and 73 subjects with $\mathrm{T} / \mathrm{C}$ or $\mathrm{C} / \mathrm{C}$ genotype (43.5\%). Among control families, there were 36 subjects with CYP1A1 wild-type genotype (T/T) (21.4\%) and 46 subjects with T/C or C/C genotype (27.3\%). The distribution frequencies of different CYP1A1 Mspl genotypes were significantly different between the two groups $(P=0.002$, OR $=5.050,95 \% \mathrm{Cl}=1.742-14.710)$. As to the GSTM1 genotype distribution, 16 subjects from EC families carried GSTM1 wild-type genotype (9.5\%) and 40 subjects carried null genotype (23.8\%). The distribution frequencies of different GSTM1 genotypes were also significantly different between the two groups $(P=0.001, O R=4.831$, and $95 \% \mathrm{Cl}=1.802-12.987)($ Table 2$)$.

Table 2. Correlations between CYP1A1 and GSTM1 gene polymorphisms and familial aggregation of EC.

\begin{tabular}{lcccc}
\hline Group & \multicolumn{2}{c}{ CYP1A1 gene polymorphism } & \multicolumn{2}{c}{ GSTM1 gene polymorphism } \\
\cline { 2 - 3 } & Genotype A & Genotype B+C & Wild-type genotype & Null genotype \\
\hline EC family & $13(7.7 \%)$ & $73(43.5 \%)$ & $16(9.5 \%)$ & $70(41.7 \%)$ \\
Control family & $36(21.4 \%)$ & $46(27.3 \%)$ & $42(25.0 \%)$ & \\
OR & 5.050 & 4.831 & & \\
$95 \% \mathrm{Cl}$ & $1.742-14.710$ & $1.802-12.987$ & & \\
P value & 0.002 & 0.001 & \\
\hline
\end{tabular}

\section{Interaction between CYP1A1 gene polymorphism and GSTM1 null genotype in familial aggregation of EC}

The interaction between CYP1A1 Mspl genotypes (genotype B and C) and GSTM1 null genotype played a role in familial aggregation of EC with an OR value of significant level. However, the OR value representing the association between CYP1A1 Mspl genotypes and GSTM1 non-null genotype was not significantly different from that representing the association between CYP1A1 Mspl genotypes and GSTM1 null genotype. This indicated that the interaction between CYP1A1 Mspl genotypes and GSTM1 non-null genotype had no significant effect on familial aggregation of EC (Table 3 ). 
Table 3. Interactions between CYP1A1 and GSTM1 gene polymorphisms in familial aggregation of EC.

\begin{tabular}{lcccc}
\hline Genotype & EC family & Non-EC family & OR $(95 \% \mathrm{Cl})$ & P value \\
\hline Mspl & & & & \\
A, GSTM1 non-null genotype & 3 & 26 & $0.153(0.021-1.092)$ & \\
B+C, GSTM1 non-null genotype & 10 & 11 & $1.741(1.061-2.857)$ & 0.35 \\
A, GSTM1 null genotype & 14 & 16 & $0.733(0.382-1.407)$ & \\
B+C, GSTM1 null genotype & 60 & 28 & $3.571(1.738-3.346)$ & 0.027 \\
\hline
\end{tabular}

\section{Risk factor analysis for familial aggregation of EC}

Using logistic regression analysis, we found that the source of drinking water, intake of fresh vegetables and fruits, and the CYP1A1 Mspl polymorphism were three statistically significant risk factors. Frequent intake of fresh vegetables and fruits was the protective factor $(\mathrm{OR}=0.278$, $95 \% \mathrm{Cl}=0.137-0.551)$, while river water intake $(\mathrm{OR}=3.468,95 \% \mathrm{Cl}=1.562-6.551)$ and the CYP1A1 Mspl mutant genotype $(\mathrm{OR}=2.732,95 \% \mathrm{Cl}=1.741-3.886)$ were the risk factors.

Table 4. Logistic regression analysis on GSTM1 gene polymorphisms and environmental factors.

\begin{tabular}{|c|c|c|c|c|c|c|c|}
\hline & \multirow[t]{2}{*}{ B } & \multirow[t]{2}{*}{ S.E. } & \multirow[t]{2}{*}{ Wald } & \multirow[t]{2}{*}{ Sig. } & \multirow[t]{2}{*}{$\operatorname{Exp}(B)$} & \multicolumn{2}{|c|}{$95 \% \mathrm{Cl}$ for $\operatorname{Exp}(\mathrm{B})$} \\
\hline & & & & & & Lower & Upper \\
\hline History of pasteurization & -0.582 & 0.657 & 0.783 & 0.376 & 0.559 & 0.154 & 2.027 \\
\hline Smoking & -0.764 & 1.354 & 0.319 & 0.572 & 0.466 & 0.033 & 6.612 \\
\hline Alcohol consumption & -1.048 & 1.276 & 0.675 & 0.411 & 0.351 & 0.029 & 4.272 \\
\hline Intake of spicy food & 0.017 & 0.775 & 0.000 & 0.983 & 1.017 & 0.223 & 4.641 \\
\hline Intake of salted and smoked food & 0.164 & 0.675 & 0.059 & 0.809 & 1.178 & 0.313 & 4.425 \\
\hline Drinking water & -2.649 & 0.941 & 7.921 & 0.005 & 0.071 & 0.011 & 0.447 \\
\hline Intake of fresh vegetables and fruits & -1.811 & 0.721 & 9.707 & 0.013 & 0.237 & 0.205 & 0.626 \\
\hline Mspl genotypes & 2.047 & 0.887 & 10.891 & 0.001 & 2.675 & 1.508 & 4.108 \\
\hline GSTM1 gene polymorphism & 0.712 & 0.968 & 0.529 & 0.612 & 1.172 & 0.378 & 3.697 \\
\hline
\end{tabular}

B: Berta coefficient; S.E.: Standard error; Wald: Chi square value; Sig.: significance; Exp(B): Odds ratio.

\section{DISCUSSION}

The CYP1A1 gene is localized on chromosome 15q22-24. This gene catalyzes the oxidative metabolism of carcinogenic polycyclic aromatic hydrocarbons and aromatic amines present in cigarettes and the environment, leading to carcinogenicity and mutagenicity. The T/C genotype of CYP1A1 gene involves the mutation 264 bp downstream of non-encoding poly A at the 3 ' end, which can be recognized by the restriction endonuclease Mspl. This mutation will enhance the catalytic activity or upregulate the expression of the CYP1A1 gene (Landi et al., 1994). Many studies have been devoted to the correlation between CYP1A1 Mspl polymorphism and tumors. In relevant literature reports concerning lung cancer, prostate cancer, and head and neck cancers (Ji et al., 2012; Ding et al., 2013; Liu et al., 2013), individuals carrying mutant genotypes (CC+TC) have a higher incidence of tumors. Moreover, the interaction between these mutant genotypes and a history of smoking has an impact on tumor occurrence. Others have found that CYP1A1 Mspl mutant genotypes are not necessarily associated with increased tumor incidence (Malik et al., 2010; Guo and Guo, 2012; Yu et al., 2012). The correlation between Mspl mutant genotypes and tumor incidence, especially among those with familial history of tumors, remains to be confirmed. We found that Mspl mutant genotypes contributed to familial aggregation of EC. Among EC families of the Kazakh ethnic group, the number of individuals carrying at least one CYP1A1 Mspl mutant 
genotype (T/C or $\mathrm{C} / \mathrm{C}$ ), or genotype $\mathrm{B}$ or $\mathrm{C}$, was 5.05 times greater than that among non-EC families. This indicates that CYP1A1 Mspl mutant genotypes contribute to familial aggregation. However, Moraes et al. (2012) did not discover any obvious correlation between CYP1A1 Mspl gene polymorphism and tumor occurrence among Brazilian families with very high tumor incidence. This discrepancy may be explained by ethnic differences.

Four alleles of the GSTM1 gene have been identified so far. The null allele exhibits no activity of the GSTM1 gene, and there is a decline in detoxification capacity of specific carcinogens. Some studies (Liu et al., 2010; Aghajany-Nasab et al., 2011; Jiang et al., 2011) indicate that GSTM1 null genotype is associated with tumor occurrence. We found that the EC families and non-EC families differed significantly in distribution frequencies of GSTM1 genotypes $(P=0.002, O R=$ $4.831,95 \% \mathrm{Cl}=1.802-12.987)$. The frequency of GSTM1 null genotype was increased among EC families of the Kazakh ethnic group, 4.831 times of that among non-EC families. As reported by Zhang et al. (2011), the risk of EC in individuals carrying GSTM1 null genotype was 1.33 times greater than that in individuals carrying wild-type genotype among the Asian population. These results were consistent with ours.

The CYP1A1 and GSTM1 genes, which are respectively associated with metabolism and detoxification, may act in synergy. Their interaction can become an important risk factor. Chinese scholars reported that GSTM1 null genotype increased the risk of lung cancer, especially in those also carrying CYP1A1 gene polymorphism (Chen et al., 2001). Sam et al. (2010) also drew similar conclusions after investigation respiratory and digestive canal cancers among the Indian population. We found that the interaction between CYP1A1 Mspl mutant genotypes and GSTM1 null genotype played an important role in familial aggregation of EC. This may be one underlying reason for the high incidence of EC among the Kazakh ethnic group in Xinjiang.

It is generally believed that $E C$ is a result of the combined action of genetic and environmental factors. Among various studies, smoking, consumption of alcohol, intake of spicy and hot food, and fast eating speeds are commonly associated with EC since they cause damage to esophageal mucosa. Liu et al. (2008) reported that irregular eating patterns and preference for hot and hard food contributed to incidence of EC in the Huai'an region. Logistic regression analysis was carried out in this study to identify the risk factors of familial aggregation of EC. Three risk factors of statistical significance were determined including the source of drinking water, intake of fresh vegetables and fruits, and CYP1A1 Mspl mutant genotypes. Among them, frequent intake of fresh vegetables and fruits was the protective factor, while river water intake and CYP1A1 Mspl mutant genotypes were the risk factors. An earlier study found that the risk of EC was increased by 4.763 times among Kazakh people who drank river water (Wang et al., 2007).

We demonstrated that CYP1A1 and GSTM1 gene polymorphisms played a role in familial aggregation of EC among the Kazakh ethnic group in Xinjiang. River water intake and CYP1A1 Mspl mutant genotypes were the risk factors of familial aggregation of EC, contributing to the high incidence in EC families. However, we did not prove the correlation of smoking and alcohol consumption to familial aggregation of EC owing to limited sample size and differences in major risk factors across the region. The sample size will be increased for stratified analysis in the future in order to identify additional causes for familial aggregation of EC among the Kazakh ethnic group in Xinjiang.

\section{Conflicts of interest}

The authors declare no conflict of interest. 


\section{REFERENCES}

Aghajany-Nasab M, Panjehpour M, Samiee SM, Rahimi F, et al. (2011). Glutathione S-transferase mu gene variants and colorectal cancer development-use of sequence-specific probes for an Iranian population. Asian Pac. J. Cancer Prev. 12: 1511-1515.

Chen S, Xue K, Xu L, Ma G, et al. (2001). Polymorphisms of the CYP1A1 and GSTM1 genes in relation to individual susceptibility to lung carcinoma in Chinese population. Mutat. Res. 458: 41-47.

Ding G, Xu W, Liu H, Zhang M, et al. (2013). CYP1A1 Mspl polymorphism is associated with prostate cancer susceptibility: evidence from a meta-analysis. Mol. Biol. Rep. 40: 3483-3491.

Guo R and Guo X (2012). Quantitative assessment of the associations between CYP1A1 polymorphisms and gastric cancer risk. Tumour Biol. 33: 1125-1132.

Ji YN, Wang Q, Lin XQ and Suo LJ (2012). CYP1A1 Mspl polymorphisms and lung cancer risk: an updated meta-analysis involving 20,209 subjects. Cytokine 59: 324-334.

Jiang Z, Li C and Wang X (2011). Glutathione S-transferase M1 polymorphism and bladder cancer risk: a meta-analysis involving 33 studies. Exp. Biol. Med. (Maywood) 236: 723-728.

Landi MT, Bertazzi PA, Shields PG, Clark G, et al. (1994). Association between CYP1A1 genotype, mRNA expression and enzymatic activity in humans. Pharmacogenetics 4: 242-246.

Liu L, Wu G, Xue F, Li Y, et al. (2013). Functional CYP1A1 genetic variants, alone and in combination with smoking, contribute to development of head and neck cancers. Eur. J. Cancer 49: 2143-2151.

Liu R, Yin LH, Pu YB, et al. (2008) Genetic and environmental risk factors and risk of esophageal cancer in Huaian. Cancer dist. mut. 20: 367-370.

Liu R, Yin L, Pu Y, Li Y, et al. (2010). Functional alterations in the glutathione S-transferase family associated with enhanced occurrence of esophageal carcinoma in China. J. Toxicol. Environ. Health A. 73: 471-482.

Malik MA, Upadhyay R, Mittal RD, Zargar SA, et al. (2010). Association of xenobiotic metabolizing enzymes genetic polymorphisms with esophageal cancer in Kashmir Valley and influence of environmental factors. Nutr. Cancer 62: 734-742.

Moraes LN, Borges MF, Sousa PA, Venere PC, et al. (2012). Lack of association of CYP1A1-Mspl SNP and GSTM1 null genotypes with cancer in a Brazilian family with unusually high cancer incidence. Genet. Mol. Res. 11: 1610-1617.

Sam SS, Thomas V, Reddy KS, Surianarayanan G, et al. (2010). Gene-environment interactions associated with CYP1A1 $\mathrm{Mspl}$ and GST polymorphisms and the risk of upper aerodigestive tract cancers in an Indian population. J. Cancer Res. Clin. Oncol. 136: 945-951.

Wang XM, Jie ES, Ma YQ, Chen B, et al. (2007). Xinjiang kazakh esophageal cancer risk factors case-control study. China Public Health 23: 737-738.

Yu L, Sun L, Jiang YF, Lu BL, et al. (2012). Interactions between CYP1A1 polymorphisms and cigarette smoking are associated with the risk of hepatocellular carcinoma: evidence from epidemiological studies. Mol. Biol. Rep. 39: 6641-6646.

Zhang CX, Chai YR, Wang P, et al. (2011). GSTM1 gene polymorphism and risk of esophageal cancer meta analysis. China Public Health 27: 241-243.

Zhao CH, Liu HX and Bu XM (2004). HMLH3 mismatch repair gene mutations in familial gastric cancer. World Chin. J. Digest.12: 1030-1033. 